\title{
Remifentanil Improves Breathing Pattern and Reduces Inspiratory Workload in Tachypneic Patients
}

\author{
Giuseppe Natalini MD, Antonella Di Maio MD, Antonio Rosano MD, Pierluigi Ferretti MD, \\ Michele Bertelli MD, and Achille Bernardini MD
}

\begin{abstract}
BACKGROUND: Properly titrated opiates decrease respiratory rate but do not affect tidal volume or induce respiratory acidosis. OBJECTIVE: To determine whether remifentanil improves breathing pattern or reduces inspiratory effort in patients with acute respiratory failure and tachypnea or rapid shallow breathing. METHODS: We studied 14 patients who developed tachypnea and/or rapid shallow breathing if the pressure support level was reduced. During pressure support ventilation, each patient received 30-min infusions, separated by $30 \mathrm{~min}$, of remifentanil and placebo. Measurements were obtained before commencing and before stopping each infusion, and after 3 min of unassisted breathing. The main outcomes were rapid shallow breathing index and change in pressure-time product. RESULTS: Remifentanil did not significantly affect tidal volume. During pressure support ventilation, remifentanil infusion reduced respiratory rate, pressure-time product, and cardiovascular double product (heart rate $\times$ systolic arterial pressure) without modifying the sedation score. Mean $\mathbf{P}_{\mathrm{aCO}_{2}}$ showed a small and clinically negligible increase during remifentanil, but $\mathbf{P}_{\mathrm{aCO}_{2}}$ increased more in the hypercapnic patients than in the normocapnic patients. Remifentanil reduced the rapid shallow breathing index after 3 min of unassisted breathing. CONCLUSIONS: Remifentanil improved respiratory pattern and decreased inspiratory muscles effort in patients with tachypnea or rapid shallow breathing, but did not affect oxygenation or sedation. Though the acid-base balance did not show clinically relevant changes on average, we cannot exclude the possibility that remifentanil might prolong weaning in hypercapnic patients. (ClinicalTrials.gov registration NCT00665119) Key words: remifentanil; respiratory rate; work of breathing; respiratory mechanics; conscious sedation; positive-pressure respiration; ventilator weaning; respiratory insufficiency; analgesics; opioid. [Respir Care 2011;56(6):827-833. (C) 2011 Daedalus Enterprises]
\end{abstract}

\section{Introduction}

Rapid shallow breathing, characterized by high breathing frequency and low tidal volume $\left(\mathrm{V}_{\mathrm{T}}\right)$, occurs both during acute respiratory failure and unsuccessful attempts to wean patients from mechanical ventilation. ${ }^{1-3}$ The rapid shallow breathing index (RSBI, respiratory rate divided by

\footnotetext{
All authors are affiliated with Unità di Terapia Intensiva Polifunzionale, Fondazione Poliambulanza Istituto Ospedaliero, Brescia, Italy.

The authors have disclosed no conflicts of interest.

Correspondence: Giuseppe Natalini MD, Unità di Terapia Intensiva Polifunzionale, Fondazione Poliambulanza Istituto Ospedaliero, via Bissolati 57, 25124 Brescia, Italy. E-mail: giuseppe.natalini@gmail.com.
}

DOI: $10.4187 /$ respcare.01014
$\mathrm{V}_{\mathrm{T}}$ ) predicts weaning outcome, ${ }^{4}$ extubation failure, ${ }^{5}$ and time to wean. ${ }^{6}$

Rapid shallow breathing is associated with increased ventilatory work load and/or reduction in respiratory muscle strength, and therefore can lead to respiratory muscle fatigue. ${ }^{7}$ Independent of its pathophysiological and clinical importance, it also increases dead-space ventilation and worsens hypercapnia. Tachypnea can generate or increase dynamic hyperinflation, which both increases the work load on the respiratory muscles and decreases their strength, efficiency, and energy supply. ${ }^{8}$ In essence, tachypnea and rapid shallow breathing can start a vicious circle toward acute respiratory failure.

Respiratory depression from opiates is characterized by decreased minute ventilation, which is related to respiratory rate reduction while $\mathrm{V}_{\mathrm{T}}$ increases. ${ }^{9}$ However, in patients with acute respiratory failure, respiratory acidosis 


\section{Remifentanil Improves Breathing Pattern and Reduces Inspiratory Workload}

and over-sedation do not occur if the opiates are properly titrated. ${ }^{10,11}$ Among the opiates, remifentanil shows the shortest context-sensitive half-life, and this feature makes it an easily titratable drug during continuous intravenous infusion. ${ }^{12,13}$

Given the effects of opiates on respiratory rate and $\mathrm{V}_{\mathrm{T}}$, we hypothesized that low-dose remifentanil could improve respiratory pattern and decrease inspiratory muscle effort by reducing respiratory rate in selected patients with acute respiratory failure.

Our aim was to determine whether remifentanil improves breathing pattern or reduces inspiratory effort, as measured by RSBI and pressure-time product (PTP), in patients with acute respiratory failure and tachypnea or rapid shallow breathing.

\section{Methods}

This study was performed in our intensive care unit, Unità di Terapia Intensiva Polifunzionale, Fondazione Poliambulanza Istituto Ospedaliero, Brescia, Italy, and was approved by our institutional ethics committee. All subjects or their next of kin gave informed consent. We studied 14 critically ill patients on pressure support ventilation (PSV), who could not be weaned from mechanical ventilation because of onset or recurrence of tachypnea or rapid shallow breathing if the pressure support was reduced or discontinued. The inclusion criteria were respiratory rate $>35$ breaths/min or RSBI $>100$ (breaths/min)/L during PSV or during weaning-readiness assessment. Readiness to wean was tested after $3 \mathrm{~min}$ at $5 \mathrm{~cm} \mathrm{H}_{2} \mathrm{O}$ continuous positive airway pressure and the same $\mathrm{F}_{\mathrm{IO}_{2}}$ used during PSV. ${ }^{14-16}$ The exclusion criteria were: vasoactive drug infusion (except dopamine at an infusion rate $<5 \mu \mathrm{g} / \mathrm{kg} / \mathrm{min}$ ), Glasgow Coma Scale $<9, \mathrm{~F}_{\mathrm{IO}_{2}}>0.6$, PEEP $>10 \mathrm{~cm} \mathrm{H}_{2} \mathrm{O}$, $\mathrm{pH}<7.30$, or concurrent administration of other sedatives or analgesics.

\section{Protocol}

Each patient received sequential 30-min infusions of remifentanil and placebo $(\mathrm{NaCl} 0.9 \%)$, separated by $30 \mathrm{~min}$ to ensure no remaining clinical effect from the remifentanil. We randomized the order of the remifentanil and placebo with a computer-generated randomization table. The infusion rate started at $5 \mathrm{~mL} / \mathrm{h}$, which could be reduced to $2.5 \mathrm{~mL} / \mathrm{h}$ if the patient developed a Richmond AgitationSedation Scale of $\leq-3$ (moderate sedation: movement or eye-opening to voice, but no eye contact). ${ }^{17}$ Remifentanil dilution was individualized to each patient's body weight to deliver $0.05 \mu \mathrm{g} / \mathrm{kg} / \mathrm{min}$ of drug at an infusion rate of $5 \mathrm{~mL} / \mathrm{h}$. The placebo and remifentanil were contained in similar syringes, and the physician conducting the study was blinded to the sequence of remifentanil and placebo.
The study protocol was interrupted if any of the following conditions occurred and lasted $>3$ min: respiratory rate $<10$ breaths/min or $>35$ breaths/min with a $20 \%$ increase over enrollment respiratory rate; $\mathrm{S}_{\mathrm{pO}_{2}}<90 \%$, systolic arterial pressure $<80 \mathrm{~mm} \mathrm{Hg}$ or $>200 \mathrm{~mm} \mathrm{Hg}$; heart rate $<50$ beats/min or $>140$ beats/min; agitation or anxiety; diaphoresis; Richmond Agitation-Sedation Scale of $\leq-4$ (deep sedation: no response to voice, but movement or eye-opening to physical stimulation).

Throughout the study we maintained all patients on the PSV settings they had at enrollment. Before and after each infusion of remifentanil or placebo, each patient underwent an unassisted breathing test similar to the above described weaning-readiness assessment.

\section{Measurements and Calculations}

We continuously monitored electrocardiography, arterial blood pressure, $\mathrm{S}_{\mathrm{pO}_{2}}$, capnography, airway pressure and flow at the airway opening (CS/3 Critical Care Monitor, Datex-Engstrom Division, Instrumentarium, Helsinki, Finland), and $\mathrm{P}_{\mathrm{es}}$, via balloon catheter (Micritek Medical, Zutphen, Holland) connected to a pressure transducer (Edwards Lifesciences, Irvine, California). Positioning and assessment of correct placement of esophageal balloon were performed as previously described. ${ }^{18}$

Arterial blood samples were analyzed (OMNI 1-9 Modular System, AVL LIST Medizintechnik, Graz, Austria) and Richmond Agitation-Sedation Scale score was collected before commencing and before stopping infusion of remifentanil or placebo, during PSV. Immediately before arterial blood sampling and during unassisted breathing tests we measured heart rate and arterial blood pressure (measured every $10 \mathrm{~s}$ ), and recorded airway pressure, $\mathrm{P}_{\mathrm{es}}$, and air flow waveforms (sampling rate $100 \mathrm{~Hz}$ ) for $3 \mathrm{~min}$ and converted the recordings to ASCII files (S/5 Collect, Datex-Ohmeda Division, Instrumentarium, Helsinki, Finland). Data were imported to a worksheet (Excel 2003, Microsoft, Redmond, Washington) for calculations.

We recorded the mean values of heart rate, mean arterial pressure, and systolic arterial pressure. Data below the 10th percentile or above the 90th percentile were not included in the mean calculations. Cardiovascular double product was calculated as heart rate $\times$ systolic arterial pressure. ${ }^{19,20}$

We selected the last recorded minute free from swallowing artifacts on the $\mathrm{P}_{\mathrm{es}}$ tracings for waveform analysis. The following variables were measured or calculated independently by three of us (ADM, AR, and PF) for any breath: $\mathrm{V}_{\mathrm{T}}$ (as integration of the flow signal); respiratory rate; inspiratory change in $\mathrm{P}_{\mathrm{es}}\left(\Delta \mathrm{P}_{\mathrm{es}}\right.$, difference between the end-expiratory pressure and the lowest inspiratory pressure); dynamic intrinsic PEEP; and PTP (see below). The 3 authors who analyzed the data were blinded to the se- 


\section{Remifentanil Improves Breathing PATtern AND Reduces Inspiratory WorkloAd}

quence of remifentanil and placebo infusion, and we analyzed the means of the calculations.

Intrinsic PEEP was calculated as the negative change in $\mathrm{P}_{\mathrm{es}}$ from the onset of inspiratory effort to the onset of inspiratory flow. ${ }^{21} \mathrm{We}$ calculated inspiratory muscle effort during the respiratory cycle by the area subtended by $\mathrm{P}_{\mathrm{es}}$ and chest-wall static recoil pressure-time curve over inspiratory time, taking into account the intrinsic PEEP. ${ }^{22}$ Chest-wall elastance was assumed to be $9.4 \mathrm{~cm} \mathrm{H}_{2} \mathrm{O} / \mathrm{L} .{ }^{23}$ PTP was calculated as the sum of all inspiratory muscle efforts performed in 1 min. We partitioned PTP into its $V_{T}$ and intrinsic PEEP components, as previously described. ${ }^{21,22}$

\section{Outcomes}

The main outcomes were PTP and RSBI variations associated with remifentanil infusion. We measured PTP and RSBI after 30 min of drug or placebo infusion during PSV. Secondary outcomes were changes in cardiovascular double product, intrinsic PEEP, arterial $\mathrm{pH}$, and Richmond Agitation-Sedation Scale score. We also recorded adverse effects and events. Breathing pattern, inspiratory effort, and cardiovascular variables also were measured during the unassisted breathing tests.

\section{Statistical Analysis}

Data are shown as mean $\pm \mathrm{SD}$, for quantitative, continuous, normally distributed variables, or as median and IQR. In a previous study, patients with acute respiratory failure had a mean RSBI of $140 \pm 25$ (breaths $/ \mathrm{min}$ )/L. ${ }^{2}$ From that datum we calculated that 14 patients were sufficient to detect RSBI changes of $>20 \%$ with a power of $80 \%$ and a significance level of .05. We first compared the 3 conditions without remifentanil (ie, before infusion of placebo, after infusion of placebo, and before infusion of remifentanil) with repeated-measure analysis of variance or the Friedman test, as appropriate. This approach tested the hypothesis that the placebo had no effect and that the patients were stable throughout the study, thereby avoiding several multiple comparisons between study groups. Second, we evaluated the effects of remifentanil by comparing data from before and after remifentanil infusion with the paired $t$ test or Wilcoxon test, as appropriate. $P<.05$ was considered significant.

\section{Results}

At recruitment, 4 patients had both respiratory rate $>35$ breaths/min and RSBI $>100$ (breaths/min)/L, 7 had RSBI $>100$ (breaths $/ \mathrm{min}$ ) $/ \mathrm{L}$ and respiratory rate $<35$ breaths/min, and 3 had RSBI $<100$ (breaths/min)/L and respiratory rate $>35$ breaths/min. Six patients were male and 8 were female. Median and IQR values included: age $78(73-82)$ years, body mass index $25(22-26) \mathrm{kg} / \mathrm{m}^{2}$, pressure support 9 (6-10) $\mathrm{cm} \mathrm{H}_{2} \mathrm{O}$, PEEP 7 (5-10) $\mathrm{cm} \mathrm{H}_{2} \mathrm{O}$, and $\mathrm{F}_{\mathrm{IO}_{2}} 0.5(0.41-0.52)$. Acute respiratory failure was due to trauma in 4 patients, exacerbation of COPD in 3 patients, pneumonia in 3 patients, stroke in 2 patients, status epilepticus in one patient, and peritonitis in one patient. Predicted mortality, based on Simplified Acute Physiology Score II was 25\% (16-72\%). Patients were on mechanical ventilation for 5 (2-12) days before the study. Six patients were tracheotomized, 4 had orotracheal intubation, and 4 had nasotracheal intubation. No patients met the criteria for protocol interruption, and all patients completed the study. Two patients needed reduction of remifentanil infusion because of Richmond Agitation-Sedation Scale score of $\leq-3$.

Table 1 shows the respiratory variables data without remifentanil. None of the variables showed any significant differences before placebo infusion, during placebo infusion, or before remifentanil infusion.

Table 2 shows the respiratory variables data before and after 30 min of remifentanil infusion. During remifentanil infusion, respiratory rate decreased, but $\mathrm{V}_{\mathrm{T}}$ was unaffected. RSBI did not change during PSV, but RSBI decreased during unassisted breathing during remifentanil. During both PSV and unassisted breathing test, remifentanil decreased $\Delta \mathrm{P}_{\mathrm{es}}$, intrinsic PEEP, $\mathrm{V}_{\mathrm{T}}$-related PTP, intrinsicPEEP-related PTP, heart rate, arterial blood pressure, and cardiovascular double product. Remifentanil also slightly decreased $\mathrm{pH}$ and slightly increased $\mathrm{P}_{\mathrm{aCO}}$, although not to the point of respiratory acidosis, on average. Nevertheless before remifentanil, 5 patients had $\mathrm{P}_{\mathrm{aCO}_{2}} \geq 45 \mathrm{~mm} \mathrm{Hg}$ (median and IQR $\mathrm{P}_{\mathrm{aCO}_{2}} 52$ [48-62] $\mathrm{mm} \mathrm{Hg}$ ), and 9 were normocapnic $\left(\mathrm{P}_{\mathrm{aCO}_{2}} 36[32-38] \mathrm{mm} \mathrm{Hg}\right)(P=.01)$. During remifentanil infusion, $\mathrm{P}_{\mathrm{aCO}}$ increased in the hypercapnic patients more than in the normocapnic patients (7 [611] $\mathrm{mm} \mathrm{Hg}$ vs 4 [3-4] $\mathrm{mm} \mathrm{Hg}$, respectively, $P=.03$ ). One patient, who had compensated respiratory acidosis before remifentanil, developed respiratory acidemia during remifentanil $\left(\mathrm{P}_{\mathrm{aCO}_{2}} 68 \mathrm{~mm} \mathrm{Hg}, \mathrm{pH}\right.$ 7.31). Remifentanil did not affect oxygenation. There were no significant changes in sedation status, but there was a trend toward a mild increase in sedation. No patient had diaphoresis, agitation, anxiety, or Richmond Agitation-Sedation Scale $\leq-4$ during unassisted breathing test. There were no other adverse effects associated with remifentanil.

\section{Discussion}

Remifentanil reduced PTP during PSV, reduced both PTP and RSBI during short unassisted breathing, and reduced the double product, a marker of myocardial oxygen consumption, independent of the ventilation mode. These changes were not associated with acidosis, over-sedation, 


\section{Remifentanil Improves Breathing PATtern AND Reduces Inspiratory WorkloAd}

Table 1. Respiratory Variables Without Remifentanil*

\begin{tabular}{|c|c|c|c|c|c|c|c|c|}
\hline & \multicolumn{4}{|c|}{ Pressure Support Ventilation } & \multicolumn{4}{|c|}{ Unassisted Breathing } \\
\hline & Placebo $\mathrm{T}_{0}$ & Placebo $\mathrm{T}_{1}$ & Remifentanil $\mathrm{T}_{0}$ & $P$ & Placebo $\mathrm{T}_{0}$ & Placebo $\mathrm{T}_{1}$ & Remifentanil $\mathrm{T}_{0}$ & $P$ \\
\hline $\begin{array}{c}\text { Respiratory rate } \\
\text { (breaths/min) }\end{array}$ & $26(24-301)$ & $29(27-30)$ & $29(25-32)$ & .88 & $30 \pm 7$ & $31 \pm 5$ & $30 \pm 5$ & .92 \\
\hline $\mathrm{V}_{\mathrm{T}}(\mathrm{L})$ & $0.35(0.31-0.41)$ & $0.34(0.30-0.41)$ & $0.34(0.3-0.43)$ & .26 & $0.32 \pm 0.08$ & $0.29 \pm 0.08$ & $0.3 \pm 0.1$ & .21 \\
\hline RSBI (breaths/L/min) & $76 \pm 30$ & $78 \pm 27$ & $75 \pm 32$ & .64 & $92(80-108)$ & $112(88-128)$ & $109(90-137)$ & .53 \\
\hline Intrinsic PEEP $\left(\mathrm{cm} \mathrm{H}_{2} \mathrm{O}\right)$ & $1.3(0.8-2.6)$ & $1(0.6-1.5)$ & $1.2(0.5-1.7)$ & .93 & $1.9(0.9-2.3)$ & $1.3(0.9-2.2)$ & $1.5(0.7-2.7)$ & .53 \\
\hline $\begin{array}{l}\text { Inspiratory } \Delta \mathrm{P}_{\mathrm{es}} \\
\quad\left(\mathrm{cm} \mathrm{H}_{2} \mathrm{O}\right)\end{array}$ & $2.4(1.2-3.2)$ & $1.4(0.9-3.7)$ & $1.7(1.2-2.6)$ & .53 & $6.1 \pm 3.5$ & $5.7 \pm 3.5$ & $6.1 \pm 3.9$ & .57 \\
\hline $\mathrm{T}_{\mathrm{I}} / \mathrm{T}_{\mathrm{TOT}}$ & $0.39(0.33-0.45)$ & $0.38(0.33-0.43)$ & $0.38(0.35-0.45)$ & .05 & $0.44(0.35-0.45)$ & $0.39(0.34-0.44)$ & $0.41(0.33-0.43)$ & .20 \\
\hline PTP $\left(\mathrm{cm} \mathrm{H}_{2} \mathrm{O} \cdot \mathrm{s} / \mathrm{min}\right)$ & $60(52-78)$ & $77(45-114)$ & $71(49-98)$ & .61 & $152 \pm 75$ & $137 \pm 72$ & $145 \pm 89$ & .44 \\
\hline $\begin{array}{l}\text { PTP-intrinsic PEEP } \\
\left(\mathrm{cm} \mathrm{H}_{2} \mathrm{O} \cdot \mathrm{s} / \mathrm{min}\right)\end{array}$ & $25(16-42)$ & $29(16-44)$ & $43(16-53)$ & .75 & 49 (27-66) & $35(24-63)$ & $37(19-82)$ & .61 \\
\hline PTP-V $\mathrm{V}_{\mathrm{T}}\left(\mathrm{cm} \mathrm{H} \mathrm{H}_{2} \mathrm{O} \cdot \mathrm{s} / \mathrm{min}\right)$ & $36(16-48)$ & $32(22-73)$ & $38(26-47)$ & .26 & $97 \pm 43$ & $88 \pm 48$ & $88 \pm 50$ & .38 \\
\hline Heart rate (beats/min) & $80 \pm 8$ & $81 \pm 10$ & $81 \pm 8$ & .65 & $82 \pm 9$ & $84 \pm 11$ & $85 \pm 7$ & .34 \\
\hline $\begin{array}{l}\text { Mean arterial pressure } \\
(\mathrm{mm} \mathrm{Hg})\end{array}$ & $95 \pm 15$ & $89 \pm 12$ & $92 \pm 13$ & .23 & $97 \pm 15$ & $92 \pm 12$ & $97 \pm 12$ & .34 \\
\hline $\begin{array}{l}\text { Double product } \\
(\mathrm{mm} \mathrm{Hg} \cdot \text { beats } / \mathrm{min})\end{array}$ & $11,148 \pm 1,956$ & $11,101 \pm 1,888$ & $11,668 \pm 1,897$ & .73 & $12,158 \pm 2,053$ & $11,893 \pm 2,258$ & $12,789 \pm 1,767$ & .36 \\
\hline $\mathrm{pH}$ & $7.46(7.45-7.52)$ & $7.48(7.45-7.5)$ & $7.48(7.46-7.51)$ & .35 & NA & NA & NA & NA \\
\hline $\mathrm{P}_{\mathrm{aCO}_{2}}(\mathrm{~mm} \mathrm{Hg})$ & $43 \pm 12$ & $44 \pm 14$ & $42 \pm 11$ & .09 & NA & NA & NA & NA \\
\hline $\mathrm{P}_{\mathrm{aO}_{2}}(\mathrm{~mm} \mathrm{Hg})$ & $98(92-127)$ & $90(88-104)$ & $103(87-114)$ & .44 & NA & NA & NA & NA \\
\hline $\begin{array}{l}\text { Richmond Agitation- } \\
\text { Sedation score }\end{array}$ & -0.5 ( -1 to 0$)$ & $-1(-1$ to 0$)$ & $0(-1$ to 0$)$ & .78 & NA & NA & NA & NA \\
\hline $\begin{array}{l}* \pm \text { values are mean } \pm \text { SD. Other } \\
\mathrm{T}_{0}=\text { before commencement of inf } \\
\mathrm{T}_{1}=\text { during infusion } \\
\text { RSBI = rapid shallow breathing in } \\
\text { Intrinsic PEEP = dynamic intrinsic } \\
\Delta \mathrm{P}_{\mathrm{es}}=\text { change in esophageal press } \\
\text { PTP = pressure-time product } \\
\text { PTP-intrinsic PEEP = PTP compor } \\
\text { PTP- } \mathrm{V}_{\mathrm{T}}=\text { PTP component related } \\
\text { NA }=\text { not applicable because we } \mathrm{d}\end{array}$ & $\begin{array}{l}\text { alues are median (IQR). } \\
\text { sion } \\
\text { ex } \\
\text { positive end-expiratory } \mathrm{p} \\
\text { re } \\
\text { ent related to intrinsic PE } \\
\text { o tidal volume } \\
\text { d not take these measure }\end{array}$ & ment during unassiste & & & & & & \\
\hline
\end{tabular}

or other adverse effects. RSBI was not significantly reduced by remifentanil during PSV, but RSBI reduction was relevant after only $3 \mathrm{~min}$ of unassisted breathing test. Despite the short duration of the unassisted breathing tests, we are confident that the RSBI improvement reached its steady-state value, as it was previously shown that RSBI did not significantly change after the first 2 min of unassisted breathing. ${ }^{24}$ In unassisted breathing tests, RSBI was $111 \pm 33$ (breaths/min)/L before remifentanil, and it decreased to $83 \pm 36$ (breaths/min)/L during remifentanil. There is consensus that RSBI $<105$ (breaths/min)/L and respiratory rate $<35$ breaths/min are required as indicators of weaning readiness. ${ }^{14}$ At recruitment, all of our study patients did not meet at least one of those conditions, whereas 7 out of the 14 patients had both RSBI $<105$ (breaths/min)/L and respiratory rate $<35$ breaths/min when the weaning readiness test was repeated during remifentanil infusion.

PTP and $\Delta \mathrm{P}_{\mathrm{es}}$ were dramatically reduced by remifentanil during both PSV and unassisted breathing. In most patients, $\mathrm{P}_{\mathrm{es}}$ requires as long as $15 \mathrm{~min}$ to stabilize during a spontaneous breathing trial, ${ }^{24}$ so $\Delta \mathrm{P}_{\mathrm{es}}$ and PTP probably stabilized only during PSV, not during unassisted breathing. Nevertheless, despite its possible underestimation, the PTP decrease during spontaneous breathing may be clinically relevant. It has been suggested that a threshold PTP value of $125 \mathrm{~cm} \mathrm{H}_{2} \mathrm{O} \cdot \mathrm{s} / \mathrm{min}$ differentiates acceptable from excessively high inspiratory effort. ${ }^{25,26}$ During unassisted breathing in our 14 patients the mean PTP was $145 \pm 89 \mathrm{~cm} \mathrm{H}_{2} \mathrm{O} \cdot \mathrm{s} / \mathrm{min}$ before remifentanil, and $89 \pm 44 \mathrm{~cm} \mathrm{H}_{2} \mathrm{O} \cdot \mathrm{s} / \mathrm{min}$ during remifentanil. It is intriguing that remifentanil shifted the mean PTP from excessive to acceptable inspiratory effort. In particular, 4 patients (29\%) had PTP $>125 \mathrm{~cm} \mathrm{H}_{2} \mathrm{O} \cdot \mathrm{s} / \mathrm{min}$ before remifentanil, and $<125 \mathrm{~cm} \mathrm{H}_{2} \mathrm{O} \cdot \mathrm{s} / \mathrm{min}$ during remifentanil.

Irrespective of ventilation mode, both the $\mathrm{V}_{\mathrm{T}}$-related and intrinsic-PEEP-related components of PTP decreased. Our patients had intrinsic PEEP similar to that in mechanically ventilated patients without flow limitation, ${ }^{27}$ but despite the low intrinsic PEEP, the respiratory-rate reduction 


\section{Remifentanil Improves Breathing Pattern and Reduces Inspiratory Workload}

Table 2. Respiratory Variables Before and During Remifentanil Infusion*

\begin{tabular}{|c|c|c|c|c|c|c|c|c|}
\hline & \multicolumn{4}{|c|}{ Pressure Support Ventilation } & \multicolumn{4}{|c|}{ Unassisted Breathing } \\
\hline & $\mathrm{T}_{0}$ & $\mathrm{~T}_{1}$ & $\begin{array}{l}\text { Difference } \\
(95 \% \mathrm{CI})\end{array}$ & $P$ & $\mathrm{~T}_{0}$ & $\mathrm{~T}_{1}$ & $\begin{array}{l}\text { Difference } \\
(95 \% \mathrm{CI})\end{array}$ & $P$ \\
\hline $\begin{array}{c}\text { Respiratory rate } \\
\text { (breaths/min) }\end{array}$ & $27 \pm 7$ & $19 \pm 5$ & $8(4-12)$ & .002 & $31(27-33)$ & $20(18-23)$ & $9(6-13)$ & .002 \\
\hline $\mathrm{V}_{\mathrm{T}}(\mathrm{L})$ & $0.34(0.3-0.43)$ & $0.32(0.29-0.44)$ & $0(-0.04$ to 0.40$)$ & .80 & $0.25(0.22-0.37)$ & $0.24(0.22-0.38)$ & $0(-0.03$ to 0.02$)$ & .95 \\
\hline RSBI (breaths/L/min) & $75 \pm 32$ & $62 \pm 33$ & $13(-10$ to 35$)$ & .26 & $111 \pm 33$ & $83 \pm 36$ & $28(10-46)$ & .005 \\
\hline $\begin{array}{l}\text { Intrinsic PEEP } \\
\qquad\left(\mathrm{cm} \mathrm{H}_{2} \mathrm{O}\right)\end{array}$ & $1.2(0.5-1.7)$ & $0.6(0.5-1.2)$ & $0.5(0.1-1.1)$ & .04 & $1.5(0.7-2.7)$ & $0.9(0.5-1.3)$ & $1(0.3-1.7)$ & .009 \\
\hline $\begin{array}{l}\text { Inspiratory } \Delta \mathrm{P}_{\mathrm{es}} \\
\quad\left(\mathrm{cm} \mathrm{H}_{2} \mathrm{O}\right)\end{array}$ & $1.7(1.2-2.6)$ & $1.1(0.8-1.8)$ & $0.7(0.1-2)$ & .04 & $6.1 \pm 3.9$ & $4.3 \pm 2.5$ & $1.9(0.4-3.3)$ & .01 \\
\hline $\mathrm{T}_{\mathrm{I}} / \mathrm{T}_{\mathrm{TOT}}$ & $0.38(0.35-0.45)$ & $0.31(0.24-0.34)$ & $0.05(0.01-0.15)$ & .02 & $0.41(0.33-0.43)$ & $0.34(0.29-0.36)$ & $0.06(0.01-0.1)$ & .03 \\
\hline PTP $\left(\mathrm{cm} \mathrm{H}_{2} \mathrm{O} \cdot \mathrm{s} / \mathrm{min}\right)$ & $71(49-98)$ & $37(26-62)$ & $39(17-64)$ & .004 & $145 \pm 89$ & $89 \pm 44$ & $56(20-92)$ & .005 \\
\hline $\begin{array}{l}\text { PTP-intrinsic PEEP } \\
\left(\mathrm{cm} \mathrm{H}_{2} \mathrm{O} \cdot \mathrm{s} / \mathrm{min}\right)\end{array}$ & $41 \pm 30$ & $18 \pm 13$ & $22(8-37)$ & .006 & $37(19-82)$ & $21(11-27)$ & $28(8-59)$ & .004 \\
\hline $\begin{array}{l}\mathrm{PTP}-\mathrm{V}_{\mathrm{T}} \\
\quad\left(\mathrm{cm} \mathrm{H} \mathrm{H}_{2} \mathrm{O} \cdot \mathrm{s} / \mathrm{min}\right)\end{array}$ & $38(26-47)$ & $18(15-45)$ & $17(7-35)$ & .009 & $88 \pm 50$ & $67 \pm 31$ & $21(3-39)$ & .02 \\
\hline Heart rate (beats/min) & $81 \pm 8$ & $77 \pm 8$ & $5(2-8)$ & .005 & $85 \pm 7$ & $79 \pm 8$ & $5(3-8)$ & .001 \\
\hline $\begin{array}{l}\text { Mean arterial pressure } \\
(\mathrm{mm} \mathrm{Hg})\end{array}$ & $91(85-97)$ & $80(71-89)$ & $9(3-20)$ & .01 & $97 \pm 12$ & $88 \pm 15$ & $9(3-16)$ & .009 \\
\hline $\begin{array}{l}\text { Double product } \\
(\mathrm{mm} \mathrm{Hg} \cdot \text { beats } / \mathrm{min})\end{array}$ & $11,668 \pm 1,897$ & $9,305 \pm 2,208$ & $\begin{array}{c}2,255 \\
(1,056-3,456)\end{array}$ & .001 & $12,789 \pm 17,67$ & $10,512 \pm 1,823$ & $\begin{array}{c}2,089 \\
(1,148-3,030)\end{array}$ & $<.001$ \\
\hline $\mathrm{pH}$ & $7.48 \pm 0.05$ & $7.44 \pm 0.06$ & $0.04(0.02-0.05)$ & $<.001$ & NA & NA & NA & NA \\
\hline $\mathrm{P}_{\mathrm{aCO}_{2}}(\mathrm{~mm} \mathrm{Hg})$ & $42 \pm 11$ & $47 \pm 14$ & $-5(-8$ to -3$)$ & $<.001$ & NA & NA & NA & NA \\
\hline $\mathrm{P}_{\mathrm{aO}_{2}}(\mathrm{~mm} \mathrm{Hg})$ & $103(87-114)$ & $108(99-148)$ & $-2(-20$ to -10$)$ & .8 & NA & NA & NA & NA \\
\hline $\begin{array}{l}\text { Richmond Agitation- } \\
\text { Sedation score }\end{array}$ & $0(-1$ to 0$)$ & $-1(-1$ to -1$)$ & $1.5(0-3)$ & .09 & NA & NA & NA & NA \\
\hline $\begin{array}{l}* \pm \text { values are mean } \pm \text { SD. Otl } \\
\mathrm{T}_{0}=\text { before commencement of } \\
\mathrm{T}_{1}=\text { before stopping of infusio } \\
\text { RSBI = rapid shallow breathing } \\
\text { Intrinsic PEEP = dynamic intri } \\
\Delta \mathrm{P}_{\mathrm{es}}=\text { change in esophageal pr } \\
\mathrm{PTP}=\text { pressure-time product } \\
\text { PTP-intrinsic PEEP = PTP com } \\
\text { PTP- } \mathrm{V}_{\mathrm{T}}=\text { PTP component rela } \\
\mathrm{NA}=\text { not applicable because }\end{array}$ & $\begin{array}{l}\text { her values are median (I } \\
\text { infusion } \\
\text { on } \\
\mathrm{g} \text { index } \\
\text { nsic positive end-expirat } \\
\text { ressure } \\
\text { aponent related to Intrins } \\
\text { ted to tidal volume } \\
\text { ve did not take these me: }\end{array}$ & $\begin{array}{l}\text { tory pressure } \\
\text { sic PEEP }\end{array}$ & breathing & & & & & \\
\hline
\end{tabular}

during remifentanil approximately halved the intrinsic PEEP value. Flow limitation and acute respiratory failure of pulmonary origin generate intrinsic PEEP higher than that observed in the present study. ${ }^{27}$ In those patients remifentanil should reduce the intrinsic-PEEP-related component of PTP, and consequently overall PTP, more than we observed in our study, which could facilitate weaning by increasing the strength and efficiency of the respiratory muscles and reducing their work load. ${ }^{8}$

During remifentanil infusion, $\mathrm{P}_{\mathrm{aCO}}$ increased and $\mathrm{pH}$ decreased. Despite the fact that these changes were clinically negligible on average, in hypercapnic patients remifentanil should be considered with caution. Remifentanil increased $\mathrm{P}_{\mathrm{aCO}}$ more in hypercapnic than normocapnic patients. We cannot exclude the possibility that remifentanil could unfavorably impact weaning in hypercapnic patients.
Remifentanil mildly to moderately reduced heart rate and arterial pressure. The final effect was a reduction of the double product, which is strongly related to cardiac oxygen consumption. ${ }^{19,20}$ Occult cardiac ischemia should be suspected in patients who repeatedly fail weaning, especially patients with coronary artery disease. ${ }^{28}$ Moreover, myocardial ischemia was accompanied by an excessive increase in the double product and increased the risk of first-day weaning failure by $110 \% .{ }^{29}$ We speculate that remifentanil could help modulate the cardiovascular response during weaning in patients with coronary artery disease.

\section{Limitations}

The main limitations of this study were that we did not titrate the remifentanil dose on an individual basis, and we 


\section{Remifentanil Improves Breathing Pattern and Reduces InsPiratory WorkloAd}

used a short infusion period. The remifentanil infusion rate $(0.05 \mu \mathrm{g} / \mathrm{kg} / \mathrm{s})$ was chosen because it reduced respiratory rate without causing respiratory acidosis in patients with acute respiratory failure. ${ }^{10}$ The clinical effects of remifentanil change within a few minutes of infusion-rate change, because of remifentanil's ultra-short context-sensitive halflife, ${ }^{12,13}$ so if we had titrated the remifentanil infusion rate on, for instance, RSBI or Richmond Agitation-Sedation Scale, more patients might have had RSBI $<105$ (breaths/ $\mathrm{min}) / \mathrm{L}$ and respiratory rate $<35$ breaths/min, without over-sedation. Nevertheless, a $0.05 \mu \mathrm{g} / \mathrm{kg} / \mathrm{s}$ remifentanil infusion rate was a safe starting dosage, considering that our subjects were mostly elderly. Finally, a 30-min infusion period did not ensure that remifentanil had reached its peak effect on minute ventilation, which could occur later, ${ }^{30}$ but, again, the short context-sensitive half-life of remifentanil should allow fast adjustment of dosage in case of excessive respiratory depression.

Remifentanil seems to be preferable to propofol or benzodiazepines when sedation is required in difficult-to-wean patients. In fact, propofol was associated with development of rapid shallow breathing in patients preparing to wean from mechanical ventilation. ${ }^{31}$ Moreover, analgesiabased sedation with remifentanil reduced the duration of mechanical ventilation and improved the weaning process, compared to benzodiazepine-based sedation. ${ }^{32}$ Further clinical trials should evaluate whether the effects of remifentanil on respiratory and cardiovascular variables can be exploited in the clinical management of patients with impending respiratory failure or during weaning. It is probable that other opiates share remifentanil's respiratory and cardiovascular effects during acute respiratory failure. In fact, fentanyl showed efficacy and safety similar to remifentanil in mechanically ventilated patients when both drugs were administered with an algorithm requiring frequent monitoring and adjustment on a sedation scale. ${ }^{33}$

\section{Conclusions}

Remifentanil decreased inspiratory muscle effort and improved ventilatory pattern in mechanically ventilated patients with tachypnea or rapid shallow breathing. Remifentanil, and probably other opiates, could be used in patients who remain tachypneic despite pressure support titration. Moreover, they should be considered as an effective choice for patients requiring sedation during weaning. Further clinical trials should evaluate whether remifentanil and other opiates reduce the need for mechanical ventilation or support the weaning process in this type of patient.

\section{REFERENCES}

1. Tobin MJ, Perez W, Guenther SM, Semmes BJ, Mador MJ, Allen SJ, et al. The pattern of breathing during successful and unsuccessful trials of weaning from mechanical ventilation. Am Rev Respir Dis 1986;134(6):1111-1118.

2. Del Rosario N, Sassoon CS, Chetty KG, Gruer SE, Mahutte CK. Breathing pattern during acute respiratory failure and recovery. Eur Respir J 1997;10(11):2560-2565.

3. Vassilakopoulos T, Zakynthinos S, Roussos C. The tension-time index and the frequency/tidal volume ratio are the major pathophysiologic determinants of weaning failure and success. Am J Respir Crit Care Med 1998;158(2):378-385.

4. Yang KL, Tobin MJ. A prospective study of indexes predicting the outcome of trials of weaning from mechanical ventilation. N Engl J Med 1991;324(21):1445-1450.

5. Frutos-Vivar F, Ferguson ND, Esteban A, Epstein SK, Arabi Y, Apezteguía C, et al. Risk factors for extubation failure in patients following a successful spontaneous breathing trial. Chest 2006;130(6): 1664-1671.

6. Aboussouan LS, Lattin CD, Anne VV. Determinants of time-toweaning in a specialized respiratory care unit. Chest 2005;128(5): 3117-3126.

7. American Thoracic Society/European Respiratory Society. ATS/ERS Statement on respiratory muscle testing. Am J Respir Crit Care Med 2002;166(4):518-624.

8. Roussos C, Koutsoukou A. Respiratory failure. Eur Respir J 2003; 22(Suppl 47):3S-14S.

9. Leino K, Mildh L, Lertola K, Seppälä T, Kirvelä O. Time course of changes in breathing pattern in morphine- and oxycodone-induced respiratory depression. Anaesthesia 1999;54(9):835-840.

10. Cavaliere F, Antonelli M, Arcangeli A, Conti G, Costa R, Pennisi MA, Proietti R. A low-dose remifentanil infusion is well tolerated for sedation in mechanically ventilated, critically-ill patients. Can J Anaesth 2002;49(10):1088-1094.

11. Conti G, Arcangeli A, Antonelli M, Cavaliere F, Costa R, Simeoni F, Proietti R. Sedation with sufentanil in patients receiving pressure support ventilation has no effects on respiration: a pilot study. Can J Anaesth 2004;51(5):494-499.

12. Egan TD, Lemmens HJ, Fiset P, Hermann DJ, Muir KT, Stanski DR, Shafer SL. The pharmacokinetics of the new short-acting opioid remifentanil (GI87084B) in healthy adult male volunteers. Anesthesiology 1993;79(5):881-892.

13. Kapila A, Glass PS, Jacobs JR, Muir KT, Hermann DJ, Shiraishi M. Measured context-sensitive half-times of remifentanil and alfentanil. Anesthesiology 1995;83(5):968-975.

14. Boles JM, Bion J, Connors A, Herridge M, Marsh B, Melot C, et al Weaning from mechanical ventilation. Eur Respir J 2007;29(5):10331056.

15. Esteban A, Frutos F, Tobin MJ, Alía I, Solsona JF, Valverdú I, et al A comparison of four methods of weaning patients from mechanical ventilation. Spanish Lung Failure Collaborative Group. N Engl J Med 1995;332(6):345-350.

16. Ely EW, Baker AM, Dunagan DP, Burke HL, Smith AC, Kelly PT, et al. Effect on the duration of mechanical ventilation of identifying patients capable of breathing spontaneously. N Engl J Med 1996; 335(25):1864-1869.

17. Ely EW, Truman B, Shintani A, Thomason JW, Wheeler AP, Gordon S, et al. Monitoring sedation status over time in ICU patients: reliability and validity of the Richmond agitation-sedation scale (RASS). JAMA 2003;289(22):2983-2991.

18. Baydur A, Behrakis P, Zin W, Jaeger M, Milic-Emili J. A simple method for assessing the validity of the esophageal balloon technique. Am Rev Respir Dis 1982;126(5):788-791.

19. Kitamura K, Jorgensen CR, Gobel FL, Taylor HL, Wang Y. Hemodynamic correlates of myocardial oxygen consumption during upright exercise. J Appl Physiol 1972;32(4):516-522. 


\section{Remifentanil Improves Breathing Pattern and Reduces Inspiratory Workload}

20. Rooke GA, Feigl EO. Work as a correlate of canine left ventricular oxygen consumption, and the problem of catecholamine oxygen wasting. Circ Res 1982;50(2):273-286.

21. Jubran A, Tobin MJ. Pathophysiologic basis of acute respiratory distress in patients who fail a trial of weaning from mechanical ventilation. Am J Respir Crit Care Med 1997;155(3):906-915.

22. Sassoon CS, Light RW, Lodia R, Sieck GC, Mahutte CK. Pressuretime product during continuous positive airway pressure, pressure support ventilation, and T-piece during weaning from mechanical ventilation. Am Rev Respir Dis 1991;143(3):469-475.

23. Katz JA, Zinn SE, Ozanne GM, Fairley HB. Pulmonary, chest wall, and lung-thorax elastances in acute respiratory failure. Chest 1981; 80(3):304-311.

24. Jubran A, Grant BJ, Laghi F, Parthasarathy S, Tobin MJ. Weaning prediction: esophageal pressure monitoring complements readiness testing. Am J Respir Crit Care Med 2005;171(11):1252-1259.

25. Jubran A, Van de Graaff WB, Tobin MJ. Variability of patientventilator interaction with pressure support ventilation in patients with chronic obstructive pulmonary disease. Am J Respir Crit Care Med 1995;152(1):129-136.

26. Foti G, Cereda M, Banfi G, Pelosi P, Fumagalli R, Pesenti A. Endinspiratory airway occlusion: a method to assess the pressure developed by inspiratory muscles in patients with acute lung injury undergoing pressure support. Am J Respir Crit Care Med 1997;156(4): 1210-1216.

27. Armaganidis A, Stavrakaki-Kallergi K, Koutsoukou A, Lymberis A, Milic-Emili J, Roussos C. Intrinsic positive end-expiratory pressure in mechanically ventilated patients with and without tidal expiratory flow limitation. Crit Care Med 2000;28(12):3837-3842.

28. Chatila W, Ani S, Guaglianone D, Jacob B, Amoateng-Adjepong Y, Manthous CA. Cardiac ischemia during weaning from mechanical ventilation. Chest 1996;109(6):1577-1583.

29. Srivastava S, Chatila W, Amoateng-Adjepong Y, Kanagasegar S, Jacob B, Zarich S, Manthous CA. Myocardial ischemia and weaning failure in patients with coronary artery disease: an update. Crit Care Med 1999;27(10):2109-2112.

30. Dershwitz M, Hoke JF, Rosow CE, Michalowski P, Connors PM, Muir KT, Dienstag JL. Pharmacokinetics and pharmacodynamics of remifentanil in volunteer subjects with severe liver disease. Anesthesiology 1996;84(4):812-820.

31. Khamiees M, Amoateng-Adjepong Y, Manthous CA. Propofol infusion is associated with a higher rapid shallow breathing index in patients preparing to wean from mechanical ventilation. Respir Care 2002;47(2):150-153

32. Breen D, Karabinis A, Malbrain M, Morais R, Albrecht S, Jarnvig IL, et al. Decreased duration of mechanical ventilation when comparing analgesia-based sedation using remifentanil with standard hypnotic-based sedation for up to 10 days in intensive care unit patients: a randomised trial. Crit Care 2005;9(3):R200-R210.

33. Muellejans B, López A, Cross MH, Bonome C, Morrison L, Kirkham AJ. Remifentanil versus fentanyl for analgesia based sedation to provide patient comfort in the intensive care unit: a randomized, double-blind controlled trial. Crit Care 2004;8(1):R1-R11. 